\title{
The role of glutamine synthetase, glutamate synthase and glutamate dehydrogenase in ammonia assimilation by the mycorrhizal fungus Pisolithus tinctorius
}

\author{
J.L. Kershaw and G.R. Stewart \\ Departement of Biology (Darwin), University College London, Gower St., London WC1E, U.K.
}

\section{Introduction}

Of the major nutrients required by trees, nitrogen appears to be the most important for increasing forest productivity. Nitrogen is obtained from inorganic forms present in the soil solution, and thus the root is an important centre for inorganic nitrogen assimilation. There is evidence that ectomycorrhizae (ECM) stimulate ammonia uptake by woody plants. The fungal partner contributes nitrogen to the tree root in two ways: by translocation of nitrogenous compounds from the soil N-pool to the root, and by conversion of absorbed $\mathrm{N}$ into forms more easily utilised by the root. Studies of the assimilation of nitrogen by pure cultures of ECM fungi provide the basis for investigation of fungal-based nitrogen metabolism within the ECM.

In most fungi and higher plants, inorganic nitrogen is assimilated into the amino acids glutamate and glutamine, which then donate nitrogen to other metabolites. The route of ammonia assimilation found in both mycorrhizal and non-mycorrhizal roots appears to be the glutamate synthase cycle, whereas ammonia assimilation in fungi is generally held to occur via the glutamate dehydrogenase (GDH) pathway (Fig. 1). Previous studies have shown that some yeasts are capable of utilising the glutamate synthase cycle for ammonia assimilation (Roon et al., 1974; Johnson and Brown, 1974), but in the ectomycorrhizal fungus Cenococcum graniforme the GDH pathway was the primary route of ammonia incorporation (Genetet et al., 1984).

\section{Materials and Methods}

Pure cultures of Pisolithus tinctorius, an ectomycorrhizal basidiomycete, were grown for $18 \mathrm{~d}$ in half-strength modified Melin-Norkrans medium (1/2MMN) containing $1 \mathrm{mM}$ ammonium. Ammonium concentration in the flasks was effectively 0 after $12 \mathrm{~d}$ of static growth at $25^{\circ} \mathrm{C}$.

Mycelia were harvested daily following the commencement of vegetative growth (d 4) and 


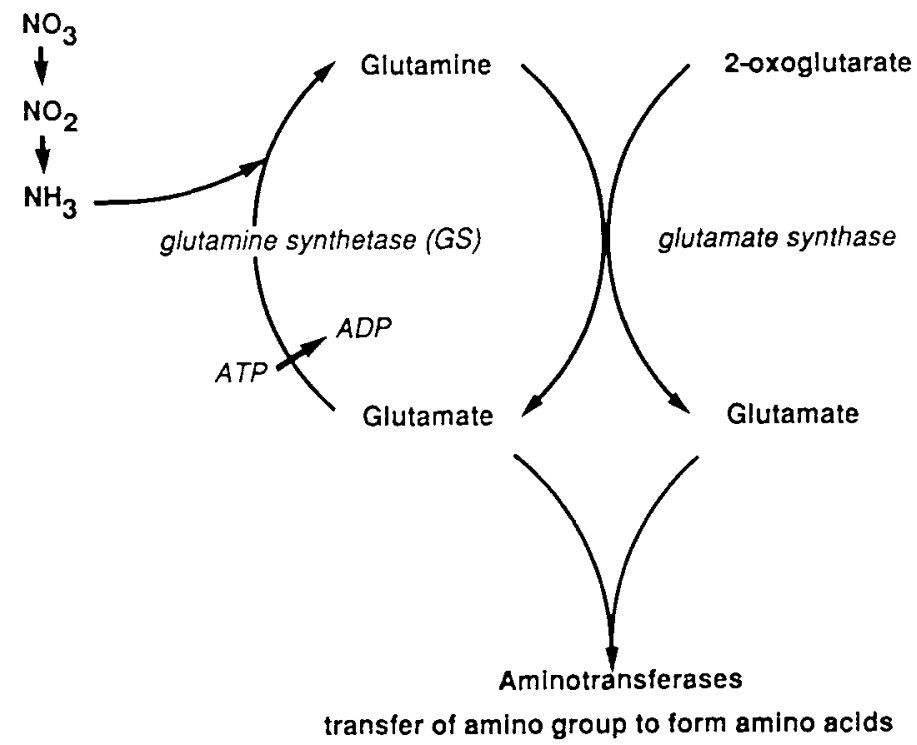

The glutamate synthase cycle

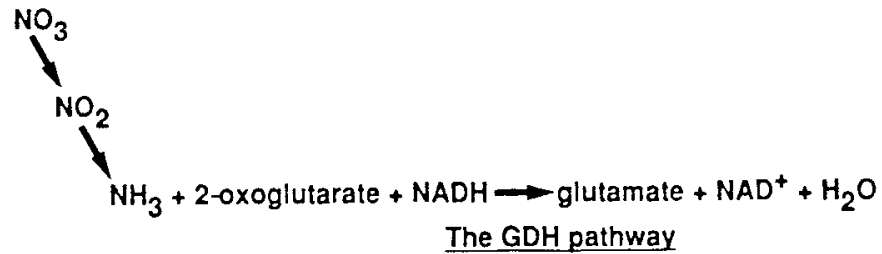

Fig. 1. Routes for ammonia assimilation into glutamate and glutamine.

assayed for glutamine synthetase (GS) activity by the biosynthetic assay, and for NADPH and $\mathrm{NADH}$-dependent GDH activity (Lea, 1985).

After 17 or $18 \mathrm{~d}$ growth, the nitrogen-starved mycelia were transferred to flasks of fresh 1/2MMN medium containing: a) no inhibitors (control), or b) methionine sulphoximine (MSX) (1 $\mathrm{mM})$, an irreversible inhibitor of $\mathrm{GS}$, or $\mathrm{c}$ ) azaserine $(1 \mathrm{mM})$, a glutamate synthase inhibitor, or d) aminooxyacetate $(0.2 \mathrm{mM})$, an inhibitor of aminotransferase enzymes. After 2, 4, 6 or $8 \mathrm{~h}$ in the fresh medium, mycelia were extracted with sulphosalicylic acid solution (0.1 M). The supernatant was assayed for amino acids by separation of the o-phthaldialdehyde derivatives on a reverse-phase HPLC column.

\section{Results}

Enzyme assays

NAD-dependent GDH activity was found to be negligible. NADP-dependent GDH 
activity was detected and found to be relatively constant throughout the period of growth (4-14 d) (Fig. 2b). GS activity was generally higher during the initial period of rapid growth (5-10 d) and decreased thereafter with ammonium concentration (Fig. 2a).

\section{Ammonia assimilation}

All extracts were found to contain significant amounts of arginine, which is thought to play a major role in nitrogen storage. Arginine was the most abundant amino acid in the nitrogen-starved mycelia $(0.8$ $\mu \mathrm{mol} / \mathrm{g}$ fresh weight). Free amino acid pool sizes of glutamate and glutamine were $0.38 \mu \mathrm{mol} / \mathrm{g}$ and $0.19 \mu \mathrm{mol} / \mathrm{g}$ fresh weight, respectively, in the $\mathrm{N}$-starved mycelia.

Rapid ammonia assimilation was shown in the controls by marked increase in the glutamate and glutamine pools after $2 \mathrm{~h}$ in the fresh medium (Fig. 3a). Glutamate levels remained constant after $2 \mathrm{~h}$ but the glutamine concentration continued to increase up to $6 \mathrm{~h}$ indicating glutamine as the primary product of assimilated ammonia.

When GS activity was inhibited by MSX (Fig. 3b), glutamine concentration failed to increase as in the control samples. An initial small increase in glutamine concentration was probably due to a lag in GS inhibition by MSX. The increase in the glutamate pool appeared to indicate assimilation of ammonia into glutamate by GDH activity.

Inhibition of glutamate synthase by azaserine blocked the transfer of amide nitrogen from glutamate to glutamine (Fig. 3c). The size of the glutamate pool did not increase over $8 \mathrm{~h}$, thus there was no incorporation of ammonia into glutamate a

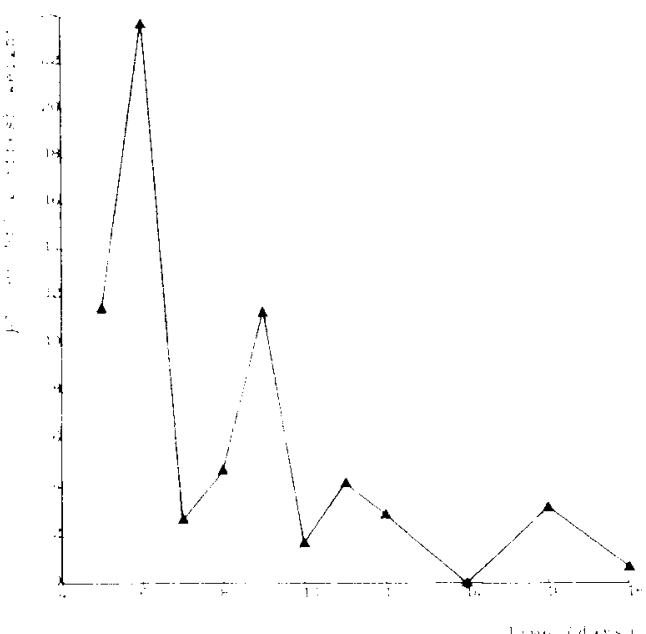

b

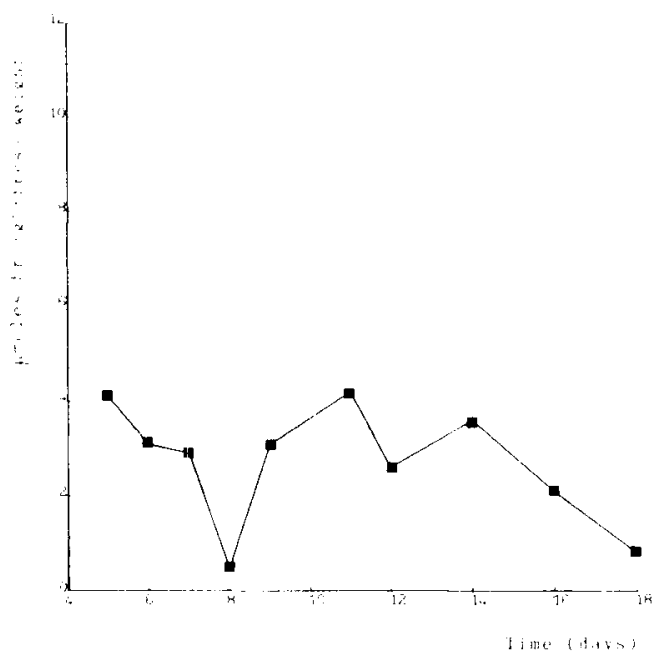

Fig. 2. Enzyme activity during vegetative growth of $P$. tinctorius. a. Glutamine synthetase. b. Glutamine dehydrogenase. 
a

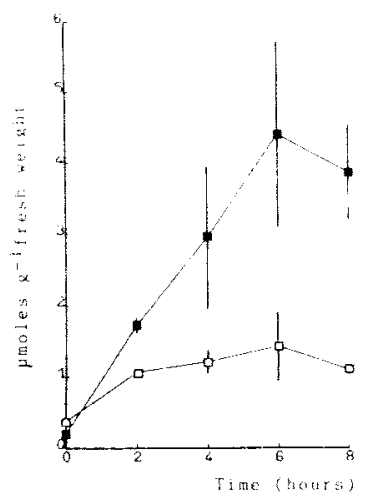

C

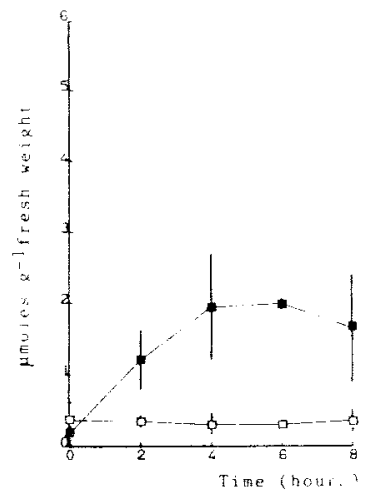

b

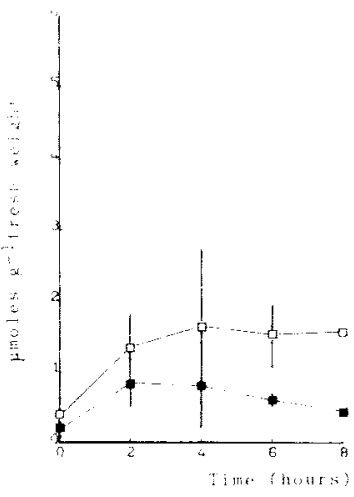

d

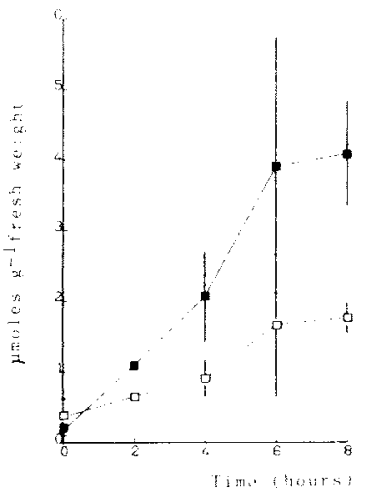

Fig. 3. Assimilation of ammonia into glutamate and glutamine by $\mathrm{N}$-starved mycelia of $P$. tinctorius. a. Control. $\mathbf{b}$. GS inhibition by MSX. c. Glutamine synthase inhibition by azaserine. d. Aminotransferase inhibition by aminooxyacetale. $\square$ : glutamate; $\mathbf{E}$ : glutamine.

by GDH. After $4 \mathrm{~h}$ the glutamine concentration peaked and remained stable, indicating feedback control of GS.

Inhibition of aminotransferases (Fig. 3d) led to an accumulation of glutamate after $6 \mathrm{~h}$, showing glutamate to be important in the donation of nitrogen for the anabolism of nitrogenous metabolites.

\section{Discussion and Conclusions}

Enzyme assays showed that the ECM fungus $P$. tinctorius was capable of ammonia assimilation by both GS and GDH activities, and that both pathways were operative during the period of high ammonia availability. 
Ammonia was assimilated primarily into the amide of glutamine by the activity of GS, and transferred to glutamate-amino by glutamate synthase activity. Inhibition of GS and glutamate synthase blocked the synthesis of glutamine and glutamate, respectively. When GS was inhibited, some glutamine was synthesised initially, and this may have accounted for the increase in glutamate concentration in this experiment, rather than GDH activity. $P$. tinctorius appeared to assimilate ammonia via the glutamate synthase cycle, with no significant role played by $\mathrm{GDH}$.

\section{References}

Genetet I., Martin F. \& Stewart G.S. (1984) Nitrogen assimilation in mycorrhizas. Plant Physiol. 76, 395-399

Johnson B. \& Brown C.M. (1974) Enzymes of ammonia assimilation in Schizosaccharomyces spp and in Saccharomycodes ludwigii. J. Gen. Microbiol. 85, 169-172

Lea P.J. (1985) In: Techniques in Bioproductivity and Photosynthesis. (Coombs J., Hall D.O., Long S.P. \& Scurlock J.M.O., eds.), Pergamon Press, Oxford, pp. 173-187

Roon R.R., Even H.L. \& Latimore E. (1974) Glutamate synthase: properties of the reduced NAD-dependent enzyme from Saccharomyces cerevisiae. J. Bacteriol. 118, 89-95 